\title{
Exploring an integrated palliative care model for older people: An integrative review
}

\begin{abstract}
:
Purpose Due to an international ageing population, global health organisations have recognised challenges arising from fragmented interaction between health and social sectors in end of life care. This paper shall explore existing literature on integrative palliative care services for older people.
\end{abstract}

Design An integrative review was conducted using the Preferred Reporting Items for Systematic reviews and Meta-Analyses (PRISMA), papers included in the review focussed upon integrated care within palliative care systems (Jan 2007-17); papers were excluded when focussed on individuals younger than 65, not written in English and not being focused on integrated palliative care.

Findings- Nine studies fitted the inclusion criteria and three themes were identified: Personcentred care, coordination of care, and education and training. The review identifies that integrated palliative care requires coordinated techniques that focus upon quality of life, individual needs and awareness of vulnerability rather than fixation on inevitable mortality.

Research Implications- The emerging presence of the need for integrated palliative care requires further research in order to develop coherent models of integrated palliative care which can be incorporated into practice.

Originality/Value- This review identified themes relevant to emerging issues in the global health sector of end of life care. The literature suggests that the optimised use of an integrated care approach to a palliative model of care is required and in need of further investigation.

Keywords: Integrated Care, Palliative Care, Older people, Multidisciplinary, Coordinated care, Person-centred care

Paper Type: Literature Review 


\section{Introduction}

Due to a $40 \%$ increase in the proportion of individuals aged 65 and older there are increasing public health concerns regarding an ageing population (Jin et al. 2015). Prompting the World Health Organisation (WHO) to declare the phenomenon as a demographic milestone (WHO, 2017). Prevalence of chronic health conditions increases with age (Piazza et al. 2007) and, multi-morbidity is more common amongst older people provoking the need for palliative care (White et al. 2016). Chouvarda et al. (2015) proposes that this demographic shift brings about new healthcare needs of older people transitioning into end of life care. This has been recognised by the WHO (2017) who argues that a more suitable health policy is required; one which addresses socioeconomic needs relating to a higher demand for end of life care.

There are multiple definitions of what constitutes palliative care, for the purpose of this paper, palliative care is defined as "an approach that improves the quality of life of patients and their families facing the problem associated with life-threatening illnesses" (WHO 2017). The unpredictable journey towards the end of one's life can lead to endless hospital admissions and overlap in the management of palliative care (Main et al. 2006). Pizzo et al. (2014) highlights that specialists in palliative care are trained to provide patients and their loved ones with emotional support when they are making decisions, encouraging transparency of information between health disciplines. In contrast, Carson et al. (2016) argues there is a lack of coordination in decision making and care goals which creates failed expectations for both health professionals and patients in palliative care. Research by the King's Fund (2015) signifies that communication is a key issue in care coordination and the development of outcomes for older people receiving palliative care services. These barriers in palliative care articulate a need for an integrated care approach improving coordination, communication, and fragmentation currently residing in end of life care.

Leutz (1999:1) envisioned that the outcome of integrated services "could address cross-system care problems, including poor coordination....and frustration for users in accessing services". Integrated care has evolved into systems of care which features integration at multiple levels: clinical, professional, organisational, and systematic (Valenitjin et al. 2015). At the heart of these perspectives is that integrated care can offer solutions to fragmented health and social care (Stange, 2009). Busetto (2016) argues that integrated care is the most promising solution for improving quality of care for older patients experiencing palliative care. By encompassing an integrated care approach to palliative care, it can improve the standards of healthcare through 
the improvement of coordination of care between health disciplines (De Stampa et al. 2013). The WHO report on palliative care (2011) calls for the development of an integrated palliative model of care that will link healthcare professionals from health and social segments of care, rather than further fragment them (Ling et al. 2010). To achieve this there is a need to understand the barriers and challenges to an integrated palliative model of care.

\section{Methods}

The aim of the review was to understand the literature surrounding an integrated palliative model of care. An integrative review methodology was chosen as it enables inclusion of both empirical and non-empirical literature (Whittemore and Knafl 2005).

\section{Search Strategy}

The Preferred Reporting Items for Systematic reviews and Meta-Analyses (PRISMA) checklist (Liberati et al. 2009) framed the searching and reporting of the review, whilst an adapted version of the PICO Framework (Bettany-Saltikov 2012) was used to identify search terms (table 1). Inclusion criteria included papers published in English between Jan 2007-2017, whilst papers were excluded if they focussed upon individuals younger than 65 and not focussed on integrated, palliative care (table 2). MySearch Bournemouth University's version of the EBSCO Discovery Service tool was used to search multiple databases including, CINAHL, MEDLINE, PubMed, and Cochrane Review.

\section{Screening and Selection}

The original search identified 190 hits which were reduced to 115 following removal of duplicates. Following this, there was a two stage screening process, at the first stage, titles and abstracts were reviewed alongside the inclusion and exclusion criteria; at this stage 74 papers were excluded. The remaining 41 papers were then read in full in the second stage and a further 32 were excluded at this stage. Reasons for exclusion included unmet age criteria, secondary focus (i.e. integrated care, palliative care, education, or technological advancement), conference/poster abstracts, and proposed frameworks. This resulted in nine articles which met the criteria for inclusion in the review (Table 3). The quality of the research was also reviewed at this stage using critical appraisal tools programme (CASP) (2017). A synthesis was performed by compiling and categorising the data using thematic groups for the identification of interests and central concepts related to the topic. The three themes identified in this review included: person-centred care, coordination of care, and education and training. 


\section{Results}

\section{Study Characteristics}

Of the nine articles included, four of them were reviews (McCormick, 2012; Burns and Nair, 2014; Duffy et al. 2011; Chan et al. 2016), six were empirical studies including qualitative research (Phillips et al. 2008; Ho et al. 2016) and mixed method research (Bergman et al. 2014; Hanratty et al. 2014; Marshall et al. 2011). The review included papers from diverse geographical regions, significant to a global outlook on integrated palliative care, including the United Kingdom $(n=4)$, United States $(n=2)$, New Zealand $(n=1)$, Australia $(n=1)$, and China $(n=1)$.

\subsection{Person-Centred Care}

The importance of taking a person-centred care approach in integrated palliative care was highlighted in seven of the nine papers (Hanratty et al. 2014; Marshall et al. 2011; Phillips et al. 2008; Bergman et al. 2016; Ho et al. 2016; Duffy et al. 2011; Chan et al. 2016). In an integrated palliative care clinic in the United States (Bergman et al. 2016), participants revealed that quality of care was improved due to an enhanced patient-provider relationship developed from a better understanding of individual needs and by identifying the patient as a whole (Ho et al. 2016). The importance of the needs of the individual in a palliative care setting was evident in 5 papers in the review (Hanratty et al. 2014; Phillips et al. 2008; Bergman et al. 2016; Duffy et al. 2011; Chan et al. 2016). Focus groups in both New Zealand and China identified that collectively sharing empathy, compassion, and devotion through integrated care helped unify actions between all stakeholders in an end of life care setting (Marshall et al. 2011; Ho et al. 2016). Yet reviews by Duffy et al (2011) and Chan et al. (2016) identified that the different aims of multiple parties involved made it more challenging to address the individual patient's needs in a coordinated, organised manner.

\subsection{Coordination of Care}

All nine articles identified a component of coordinated care as a major factor in the development of an integrated palliative care approach. Four out of the nine papers focused on the use of some form of multi-disciplinary team as a means of positive assistance in palliative care (Phillips et al. 2008; Bergman et al. 2016; McCormick, 2012; Burns and Nair, 2014). Additionally, multidisciplinary teams in Australia found it effective to regularly meet to discuss the patients and their health status (Phillips et al. 2008). In contrast, Hanratty et al. (2014) identified that a single 
point of contact referred to as a "transition" coach (i.e. nurse leader or clinical manager), facilitated the coordination through multifaceted care levels. The importance of an organised relationship between healthcare professionals within health and social segments of palliative care was heighted by numerous papers (Hanratty et al. 2014; Marshall et al. 2011; Ho et al. 2016; McCormick, 2014; Duffy et al. 2011). According to Ho et al. (2016) this relationship led to coordinated care through effective communication, inter-professional management between all organisations and parties involved in end of life care. Whilst communication is shown as an integral part of integrated palliative care, it can occur in several diverse ways including regular updates and newsletters (Ho et al. 2016) and briefings between all members involved in care (McCormick, 2012).

\subsection{Education and Training}

Seven studies highlighted a lack of general knowledge in palliative care (Marshall et al. 2011; Phillips et al. 2008; Bergman et al. 2016; Ho et al. 2016; McCormick, 2012; Duffy et al. 2011; Chan et al. 2016). Induction into palliative care was identified as not being delivered adequately to patients (Chan et al. 2016) nor staff (Bergman et al. 2016; McCormick, 2012). In addition, the quality of the education that was offered to the health professionals did not reflect the depth that is required for palliative care (Ho et al. 2016; McCormick, 2012; Duffy et al. 2011). When integrated care was introduced as a concept to enhance palliative care, education and training resulted in a positive impact as Marshall et al. (2011) identified staff had higher confidence in preventing inappropriate transfer during end of life care. Focus groups in Australia identified that providing quality palliative care education to multi-faceted care teams prompted a collaborative integrated care approach (Phillips et al. 2008). Whilst reviews of integrated palliative care pathways revealed that staff development and staff education in palliative care, had resulted in the global needs of the patients in the palliative phase being addressed (Bergman et al. 2016; McCormick, 2012; Duffy et al. 2011; Chan et al. 2016).

\section{Discussion}

Eight out of the nine studies and reviews were conducted from 2011 onwards (Hanratty et al. 2014; Marshall et al. 2011; McCormick, 2012; Burns and Nair,2014; Bergman et al. 2016; Ho et al. 2016; Duffy et al. 2011; Chan et al. 2016), implying that research in this field is emerging. 
The results of this integrative review indicate that whilst implementing an integrated palliative model of care into practice is on the horizon, there is still a way to go to progress this. Seeing that there is a global phenomenon of an ageing across the world increases the need for integrated palliative care. For older people death is inevitable and not feared (Lloyd-Williams et al. 2007), however it is the quality of life through care that is a concern (Wetle et al. 2005). Small (2007) formulates a "too little, too much" approach in the care of older people with dementia as the individuals are frequently transitioned through different care settings or the level of care needed was simply not sufficient or person centred. The significance of a personcentred care approach was highlighted as a key aspect in this review. Older people are identified as a frail population due to an increased risk for adverse health outcomes (Fried et al. 2001) and when requiring end of life care as their degree of frailty increases (Boockvar and Meier, 2016). In recent years there has been a shift towards "at-homeness" in end of life care, where the individuals feel like they are at home irrespective of the setting (Saarnio et al. 2016).

Coulter et al. (2013) argues that health organisations require care coordination between professionals across sectors and this review identified that tailored multidisciplinary teams are at the heart of an integrated palliative model of care. The benefits to the patients of teams being organised to provide an integrated palliative model of care have been identified in a number of studies including Bergman et al., (2016) and Burns and Nair (2014). The benefits to the patients of an integrated palliative model of care have been identified in a number of studies including De Stampa et al., (2013), Duffy et al., (2011) and WHO (2011). The formation of these tailored multidisciplinary teams assisting the transition from situational to end of life care has been apparent throughout the last couple decades. The Kings Fund (2013) identified thriving multidisciplinary teams in the form of community resource teams (CRT) and esteem teams, as well as, teams led through a single point of contact (Thiel et al. 2013). Though consisting of different names and structures, the overall aim of these multidisciplinary teams were similar in that they were constructed with multiple levels of management and coordinated services within a partnership framework.

As mentioned earlier, Patel and Masi (2015) identified the lack in progressive training and quality education in palliative care. Whilst there are palliative care specialists it is important that all staff working in these areas feel they have the education they need in order to provide high levels of quality care (Harris et al. 2016). By increasing palliative care training across all disciplines, it can open awareness to the public and allows healthcare professionals to 
communicate to patients and family members about end of life care and practice. Communication has been acknowledged by Olsen et al. (2010) and as an attractive skill added by an integrated palliative model of care, although the sensitivity of the subject makes it hard for professionals to convey the need for palliative care. There have been successful training exercises that utilise interactive theatre to enhance patient-provider communication and improve the promotion of inter-professional education (Pastor et al. 2016), which is one of the essential foundations of any effective health care plan (Arnold and Boggs, 2015). Continuous engagement through constant updates and feedback developed by interdisciplinary relationships proves to engage effective communication levels (Cunniffe et al. 2016) which can be used to create a joint holistic integrated palliative model of care.

\section{Limitations}

As identified, Integrated Palliative Care is an embryonic field of practice, as such there are limited published peer reviewed papers in this emerging field. In addition, as this review focussed upon published peer review literature, we recognise that there may be other reports and grey literature in this field which were not included in this review. Although qualitative data was collected, the data from the individuals themselves was limited. This is in part a response due to the ethical considerations of the vulnerability of the patient going through end of life care and their family which contributes to the challenging nature of research in this field (Aoun and Kristjanson, 2005).

\section{Conclusion}

This integrative review has identified that an integrated palliative model of care could facilitate the delivery of person-centred care to older people who are dying is a variety of different settings. Integrated palliative care is clearly an area of increasing interest and as result concepts of integrated care are ever-changing. However, there is currently very little published research in this area and more work is needed to identify particular models of care and the impact of these on patients and their families. Nevertheless, this review has identified that provision of coordinated care, through integrated multidisciplinary teams, enhances communication and inter-professional relationships all of which can lead to a better quality of care.

\section{References}


Arnold, E.C. and Boggs, K.U., (2015), "Interpersonal Relationships-E-Book: Professional Communication Skills for Nurses. Elsevier Health Sciences, St. Louis, Missouri

Bergman, J. Ballon-Landa, E. Lorenz, K. Saucedo, J. Saigal, C.Bennett, C. Litwin, M. (2016), "Community- partnered collaboration to build an integrated palliative care clinic: The view from urology". American Journal of Hospice and Palliative Care, Vol.33 No 2, pp164-170

Bettany-Saltikov, J. (2012), "How to Do a Systematic Literature Review in Nursing: A Step-byStep Guide”. Open University Press, Maidenhead

Burns, E. Nair, S. (2014), "New Horizons in care home medicine". Age and Ageing, Vol 43, pp27

Busetto, L. (2016), "Great Expectations: The Implementation of Integrated Care and Its Contribution to Improved Outcomes for People with Chronic Conditions", International Journal of Integrated Care, Vol. 16 No., pp16

Carson, S.S. Cox, C.E. Wallenstein, S. Hanson, L.C. Danis, M. Tulsky, J.A. Chai, E. and Nelson, J.E. (2016), "Effect of palliative care-led meetings for families of patients with chronic critical illness: a randomized clinical trial", Jama, Vol 316 No. 1, pp. 51-62.

Chan, R. Webster, J. Bowers, A. (2016), "End-of-life care pathways for improving outcomes in caring for the dying", Cochrane Database of Systematic Reviews, Vol 2; CD008006.

Chouvarda, I.G. Goulis, D.G. Lambrinoudaki, I. and Maglaveras, N. (2015), "Connected health and integrated care: Toward new models for chronic disease management", Maturitas Vol. 82 No.1,pp. 22-27.

Coulter, A. Roberts, S. and Dixon, A. (2013), "Delivering better services for people with longterm conditions, building the house of care". The King's Fund, London.

Cunniffe, M. Burke, M. Curran, M. and Collier, D. (2016), "Developing people-centeredness in the Irish healthcare system - continuous awareness and communication are key enablers to success", ICIC 16th International Conference on Integrated Care, 23-25 May 2016, Barcelona, Spain.

De Stampa, M. Vedel, I. Bergman, H. Novella, J.L. Lechowski, L. Ankri, J. and Lapointe, L. (2013), "Opening the Black Box of Clinical Collaboration in Integrated Care Models for Frail, Elderly Patients”, The Gerontologist, Vol. 53 No.2, pp. 313-325.

Duffy, A. Payne, S. Timmins, F. (2011), "The Liverpool care pathway: does it improve the quality of dying?", British Journal of Nursing, Vol 20, No15, pp942-946

Fried, L.P. Tangen, C.M. Walston, J. Newman, A.B. Hirsch, C. Gottdiener, J. Seeman, T. Tracy, R. Kop, W.J. Burke, G. and McBurnie, M.A. (2001), "Frailty in older adults: evidence for 
a phenotype", The Journals of Gerontology Series A: Biological Sciences and Medical Sciences, Vol. 56 No. 3, pp.M146-M157.

Hanratty, B., Lowson, E., Grande, G., Payne, S., Addington-Hall, J., Valtorta, N. Seymour, J. 2014. "Transitions at the end of life for older adults - patient, carer and professional perspectives: a mixed-methods study". Health Services and Delivery Research Vol 2; pp.17

Harris, J.A. Herrel, L.A. Healy, M.A. Wancata, L.M. and Perumalswami, C.R. (2016), "Milestones for the Final Mile: Interspecialty Distinctions in Primary Palliative Care Skills Training", Pain and Symptom Management, Vol. 52 No.3, pp.345-352.

Ho, A. Luk, J. Chan, F. Chun Ng, W. Kwok, C. Yuen, J. Tam, M. Kan, W. Chan, C. (2016), "Dignified palliative long-term care: an interpretive systematic framework of end-of-life integrated care pathway for terminally ill Chinese older adults", Am J Hosp Palliat Care, Vol. 33, No.5; pp 439-47

Jin, K. Simpkins, J. Xunming, J. Leis, M. and Stambler, I. (2015), "The Critical Need to Promote Research of Aging and Aging-related Diseases to Improve Health and Longevity of the Elderly Population", Aging \& Disease, Vol. 6 No.1, pp. 1-5.

Kodner, D.L. and Spreeuwenberg, C. (2002), "Integrated care: meaning, logic, applications, and implications-a discussion paper", International Journal of Integrated Care, Vol.2 No.4, pp1-6

Leutz, W.N. (1999), "Five laws for integrating medical and social services: lessons from the United States and the United Kingdom", The Milbank Quarterly, Vol.77 No.1, pp.77-110.

Liberati, A. Altman, DG. Tetzlaff, J. Mulrow,C. Peter,CG. Loannidis, JPA. Clarke, M. Devereaux, PJ. Kleijnen, J. and Moher, D. (2009) "The PRISMA Statement for Reporting Systematic Reviews and Meta-Analyses of Studies That Evaluate Health Care Interventions: explanation and Elaboration", PLoS Medicine Vol.6, pp.1-28.

Ling, T. Bardsley, M. Adams, J. Lewis, R. and Roland, M. (2010), "Evaluation of UK Integrated Care Pilots: research protocol", International Journal of Integrated Care, Vol.10 No.3, pp1-15.

Lloyd-Williams, M. Kennedy, V. Sixsmith, A. and Sixsmith, J. (2007), "The end of life: a qualitative study of the perceptions of people over the age of 80 on issues surrounding death and dying", Pain and Symptom Management, Vol.34 No.1, pp.60-66.

Main, J. Whittle, C. Treml, J. Woodley, J. and Main A. (2006), "The development of an Integrated Care Pathway for all patients with advanced life-limiting illness - the Supportive Care Pathway", Nursing Management, Vol.14 No. 7, pp. 521-528 
Marshall, B. Clark, J. Sheward, K. Allan, S. (2011). "Staff perceptions of end-of-life care in aged residential care: a New Zealand perspective". J Palliat Med, Vol14, No 6, pp.688-95.

McCormick, W. (2012). "Report of the Geriatrics- Hospice and Palliative Med work group: American Geriatrics Society and American Academy of hospice and palliative medicine leadership collaboration”. Journal of the Americian Geriatric Society, Vol 60, No3, pp-1-9

Olsen, L. Saunders, R.S. and Yong, P.L. 2010. "The healthcare imperative: lowering costs and improving outcomes: workshop series summary". National Academies Press, Washington, DC.

Pastor, D.K. Ashton, C. Cunningham, R.P. Kolomer, S. Lutz, B.J. Smith, S. White, P.H. and Saypol, B. (2016), "Using interactive theater to improve provider-family communication and promote inter-professional education and practice in palliative care", Interprofessional Education \& Practice, Vol.4, pp.15-20.

Patel, K. and Masi, D. (2015), "Palliative care in the era of health care reform", Clinics in Geriatric Medicine, Vol. 31, No. 2, pp.265-270.

Phillips, J. Davidson, P. Jackson, D. Kristjanson, L (2008), "Multi-faceted palliative care interventions: aged care nurses' and care assistants' perceptions and experiences". Journal of Advanced Nursing, Vol.62, No.2, pp.216-227

Piazza, J.R. Charles, S.T. and Almeida, D.M. (2007), "Living with chronic health conditions: Age differences in affective well-being". The Journals of Gerontology Series B: Psychological Sciences and Social Sciences, Vol. 62, No. 6, pp.P313-P321.

Pizzo, P.A. Walker, D.M. and Bomba, P.A. (2014), "Dying in America: improving quality and honoring individual preferences near the end of life". Institute of Medicine, Washington, DC.

Saarnio, L. Boström, A.M. Gustavsson, P. and Öhlén, J. (2016), "Meanings of at-homeness at end-of-life among older people", Scandinavian Journal of Caring Sciences, Vol.30 No.2, pp.312-319.

Small, N. (2007), "Living well until you die". Annals of the New York Academy of Sciences, Vol. 1114 No. 1, pp.194-203.

Stange, K.C. (2009), "The problem of fragmentation and the need for integrative solutions", The Annals of Family Medicine Vol. 7 No.2, pp.100-103.

Thiel, V. Sonola, L. Goodwin, N. and Kodner, D. (2013), “The Esteem Team Co-ordinated care in the Sandwell Integrated Primary Care Mental Health and Wellbeing Service", The King's Fund, London. 
White, C. Lentin, P. and Farnworth, L. (2016), "Multimorbidity and the process of living with ongoing illness" Chronic Illness, Vol. 12 No. 2, pp.83-97.

Whittemore, R. and Knafl, K. (2005), "The integrative review: updated methodology". Advanced Nursing, Vol.52 No.5, pp.546-553.

World Health Organisation (2017), "Health Topics: Ageing", available at http://www.who.int/topics/ageing/en/ [accessed 19.9.2018]. 